\title{
Model improvement and future projection of permafrost processes in a global land surface model
}

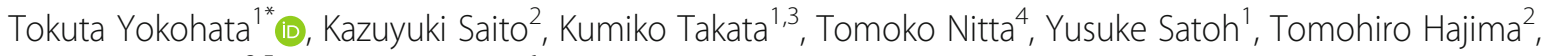
Tetsuo Sueyoshi ${ }^{2,5}$ and Go Iwahana ${ }^{6}$

\begin{abstract}
To date, the treatment of permafrost in global climate models has been simplified due to the prevailing uncertainties in the processes involving frozen ground. In this study, we improved the modeling of permafrost processes in a state-of-the-art climate model by taking into account some of the relevant physical properties of soil such as changes in the thermophysical properties due to soil freezing. As a result, the improved version of the global land surface model was able to reproduce a more realistic permafrost distribution at the southern limit of the permafrost area by increasing the freezing of soil moisture in winter. The improved modeling of permafrost processes also had a significant effect on future projections. Using the conventional formulation, the predicted cumulative reduction of the permafrost area by year 2100 was approximately $60 \%$ (40-80\% range of uncertainty from a multi-model ensemble) in the RCP8.5 scenario, while with the improved formulation, the reduction was approximately $35 \%$ (20-50\%). Our results indicate that the improved treatment of permafrost processes in global climate models is important to ensuring more reliable future projections.
\end{abstract}

Keywords: Permafrost degradation, Global climate model, Climate change

\section{Introduction}

Global warming is expected to produce a thawing of the permafrost (Koven et al. 2013; Slater and Lawrence 2013; Vaks et al. 2013; Koven et al. 2015; McGuire et al. 2018). As a result, large amounts of organic matter confined in the permafrost will decompose, releasing greenhouse gases (GHGs) such as carbon dioxide and methane (Zimov et al. 2006; Schuur et al. 2008; Brown 2013; Schaefer et al. 2014; MacDougall et al. 2015; Schneider von Deimling et al. 2015; MacDougall and Knutti 2016; Steffen et al. 2018; Gasser et al. 2018; McGuire et al. 2018; Kawamiya et al. 2020; Saito et al. 2020; Yokohata et al. 2020). Unfortunately, the permafrost processes represented in current global climate models (GCMs) tend

\footnotetext{
* Correspondence: yokohata@nies.go.jp

${ }^{1}$ Center for Global Environmental Research, National Institute for Environmental Studies, 16-2 Onogawa, Tsukuba 305-8506, Japan Full list of author information is available at the end of the article
}

to be rather simplistic because of the significant uncertainties regarding the dynamics of the permafrost due mainly to a lack of observational knowledge (Alexeev et al. 2007; Nicolsky et al. 2007; Lawrence et al. 2008; Rinke et al. 2008; Koven et al. 2009; Gouttevin et al. 2012). Projections of permafrost thawing vary substantially in distribution and magnitude depending on the climate model used (Koven et al. 2013; Slater and Lawrence 2013). This wide variation in projections can be explained by the fact that the rate of degradation of the permafrost is closely related to a variety of factors in the climate system, including changes in the surface air temperature, precipitation, and evaporation in the high latitudes, all of which involve a great deal of uncertainty.

In this study, we improved the modeling of permafrost processes in the global land surface model MATSIRO (Minimal Advanced Treatments of Surface Interaction and Runoff, Nitta et al. 2014), which is used in the global 
climate model MIROC (Model for Interdisciplinary Research on Climate, Watanabe et al. 2010). We conducted historical simulations by using both conventional schemes and our proposed scheme and compared simulation results to observations. We also conducted future simulations using the two schemes and assessed the impact of our model improvement, as well as the sources of uncertainty in future simulations.

Previous research (Lawrence et al. 2008; Saito 2008a; Saito 2008b; Saito 2011; Chadburn et al. 2015; Melton et al. 2019) has recognized the importance of taking into account changes in thermodynamic quantities due to the freezing of soil moisture and the physical characteristics of the organic layer near the ground surface, and presence of unfrozen water in order to obtain more realistic permafrost distributions in simulations using global climate models. However, this previous research with MATSIRO (Saito 2008a, 2008b, 2011) involved only historical or ideal future simulations at particular points where observational data were available (e.g., Utqiagvik, formerly known as Barrow) or conducted only historical global simulations. Consequently, neither the impact of the proposed improvements in the modeling of the physical properties of permafrost processes nor the uncertainties in the projection of future atmospheric forcing were evaluated.

This study directly addresses both issues. We first evaluate the effects of the improvements in the modeling of the physical processes related to permafrost on the reproducibility of the observed permafrost distribution and analyze the effect of these improvements on the future projection of the permafrost distribution. We also assess the effect of the uncertainties associate with the atmospheric forcings on the simulations of the permafrost distributions. For this purpose, we apply atmospheric forcings generated by bias-corrected global climate models to the global land surface model and then perform multiple future simulations.

\section{Methods}

\subsection{Improvement of permafrost processes in a global} climate model

In this study, the proposed improvements in the modeling of the permafrost processes include the following considerations:

(1) Consideration of the heat capacity and thermal conductivity of frozen soil.

(2) Consideration of the organic layer near the surface in the high-latitude Taiga and Tundra regions.

(3) Consideration of unfrozen water in regions where the ground temperature is below $0{ }^{\circ} \mathrm{C}$

The details of consideration (1) and (3) are provided in Saito (2008a). In brief, in the conventional scheme, all soil moisture is treated as liquid water when calculating soil heat capacity $C$ and thermal conductivity $K$ (Takata et al. 2003). However, frozen water has a smaller heat capacity and greater thermal conductivity than liquid water. To reflect this, in the improved scheme that we propose, when water is frozen the heat capacity is smaller and the thermal conductivity is greater than is the case in the conventional scheme (Saito 2008a, 2008b). Similarly, unfrozen water content is present but decreases exponentially with the subfreezing temperature where the exponent coefficient is predetermined by the soil types (e.g., sand, silt, and clay).

Saito (2011) gives details of the improved treatment of the organic layer as described in consideration (2). In the current study, the soil parameter values are further modified to increase model performance. The land surface model MATSIRO determines the vegetation and soil type for each grid. The six physical properties of soil (volumetric specific heat, thermal conductivity, porosity, saturated matrix potential, saturated hydraulic conductivity, void size distribution index) are then set according to the soil type (Takata et al. 2003; Saito 2011). In this study, we first determined the uncertainty ranges for these soil parameters based on expert judgement, and then perturbed these parameters one by one within the uncertainty ranges. Then, we found a parameter set for which the permafrost area obtained by the land surface model (as illustrated in Fig. 2) is close to the permafrost region estimated from observations by the International Permafrost Association (IPA; Brown et al. 1998).

For both the conventional and improved schemes described here, six vertical layers and a bottom depth of 14 $\mathrm{m}$ were used (Nitta et al. 2014). In the conventional scheme, constant physical properties are given according to soil type regardless of the vertical depth (Takata et al. 2003). The definition of soil types and the values for the six physical properties are the same as those in Nitta et al. (2014). In the improved scheme, in high-latitude regions with Tundra vegetation types, the top three layers $(0-1 \mathrm{~m})$ are organic layers, the middle two layers $(1 \mathrm{~m}-4 \mathrm{~m})$ are mineral soil layers, and the bottom layer $(4-14 \mathrm{~m})$ is the bedrock layer, mainly consisting of rocks as shown in Table 1 . In the regions with taiga vegetation type, the top four layers $(0-2 \mathrm{~m})$ are organic, the fifth layer $(2-4 \mathrm{~m})$ is mineral soil, and the bottom layer (4-14 $\mathrm{m}$ ) is the bedrock layer (Table 1). The values for the physical parameters are different depending on the type of soil layer. In the grids for regions other than the Taiga or Tundra regions, the top five layers are mineral soil layers, and the bottom layer is the bedrock layer. The soil type in the improved scheme is given in the same way as in Saito (2011). However, the values for the six physical properties have been improved. Table 1 summarizes these values for the organic, mineral, and base layers used in the improved and conventional scheme. 
Table 1 Parameter values for the organic, mineral soil, and base layers used in the improved scheme. The values for the mineral layers are dependent on the soil type. Here, the values of the mineral layers for the "sand" soil type are shown. The layers for the organic (moss and soil), mineral soil, and bed lock layer for the improved and conventional schemes are also shown

\begin{tabular}{|c|c|c|c|c|}
\hline & Organic (moss) & Organic (soil) & Mineral & Bedrock \\
\hline Layers in the improved scheme (Tundra) & Top layer $(0-5 \mathrm{~cm})$ & 2nd-3rd layers (5-1 m) & 4th-5th layers (1-4 m) & Bottom layer (4-14 m) \\
\hline Layers in the improved scheme (Taiga) & Top two layers $(0-25 \mathrm{~cm})$ & 3rd-4th layers $(25-2 m)$ & $5^{\text {th }}$ layer (2-4 m) & Bottom layer (4-14 m) \\
\hline Layers in the original scheme & - & - & All layers (0-14 m) & - \\
\hline Volumetric specific heat $\left[\mathrm{MJ} / \mathrm{m}^{3} \mathrm{~K}\right]$ & 2.5 & 2.5 & 2.1 & 2.3 \\
\hline Thermal conductivity $[\mathrm{W} / \mathrm{m} \mathrm{K}]$ & 0.12 & 0.25 & 2.0 & 3.0 \\
\hline Saturated soil moisture (porosity) [-] & 0.8 & 0.7 & 0.48 & 0.3 \\
\hline Saturated hydraulic conductivity $10^{-6}[\mathrm{~m} / \mathrm{s}]$ & 15 & 2.0 & 1.71 & 5.0 \\
\hline Saturated hydraulic potential [m] & -0.085 & -0.12 & -0.0563 & -0.300 \\
\hline Void size distribution index [-] & 2.1 & 4.0 & 3.6 & 3.3 \\
\hline
\end{tabular}

\subsection{Experimental settings}

To investigate the effect of our improvements in the modeling of the permafrost processes, we performed offline simulations using a global land surface model MATSIRO (Nitta et al. 2014). In these simulations, atmosphere-ocean processes in the global climate model MIROC (Watanabe et al. 2010) were not calculated but were given as an atmospheric forcing to drive the land surface model. For the atmospheric forcing, we used the data provided by the InterSectoral Impact Model Inter-comparison Project, Phase 1 (ISIMIP1, Hempel et al. 2013). In the ISIM IP1 forcing, atmospheric variables were calculated by five GCMs (GFDL-ES2M, Dunne et al. 2012; HadGEM2-ES, Jones et al. 2011; IPSL-CM5A-LR, Dufresne et al. 2013; Nor-ESM, Bentsen et al. 2013; MIROC-ESM-CHEM, Watanabe et al. 2011), and model bias was corrected in the historical and future simulations.

In the present study, we performed our historical and future simulations by giving the atmospheric forcings of the five GCMs to MATSIRO. The climate scenarios in the future simulations were based on Representative Concentration Pathways (RCP, van Vuuren et al. 2011); specifically, we used the lowcarbon scenario (RCP2.6) and the high-warming business-as-usual scenario (RCP8.5). The global average of the surface air temperature anomaly given as the atmospheric forcing for RCP2.6 and RCP8.5 is shown in Fig. 1.

\section{Results and discussion}

\subsection{Comparison of model simulations with observations}

Figure 2 shows the permafrost area results obtained by our MATSIRO offline simulation. The permafrost area is defined as the regions where the soil temperature is kept below $0{ }^{\circ} \mathrm{C}$ in any of the soil layers throughout the year. In Fig. 2, the permafrost region estimated from observations by the IPA (Brown et al. 1998) is outlined in black and compared to the areas estimated in the model simulations. In the MATSIRO offline simulation, the results of the GCM simulations were used as the atmospheric forcing (Section 2.2). As shown in Fig. 2, the permafrost area estimated with the improved scheme is larger than that in the conventional scheme, especially in southern Siberia and southern Canada. Importantly, the estimated area under the improved scheme shows better agreement with the observation-based estimate.

Consideration of three additional factors accounts for the superior performance of the improved version. These include (a) the heat insulation effect of the organic layer, (b) the increase in heat conduction in winter

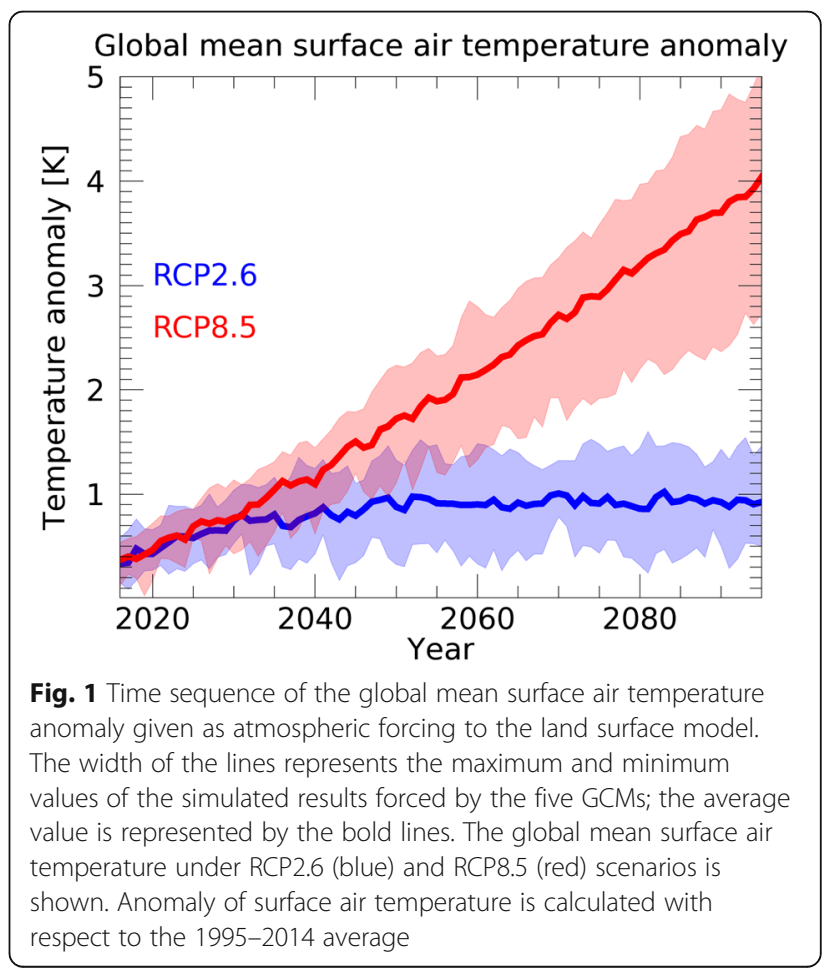




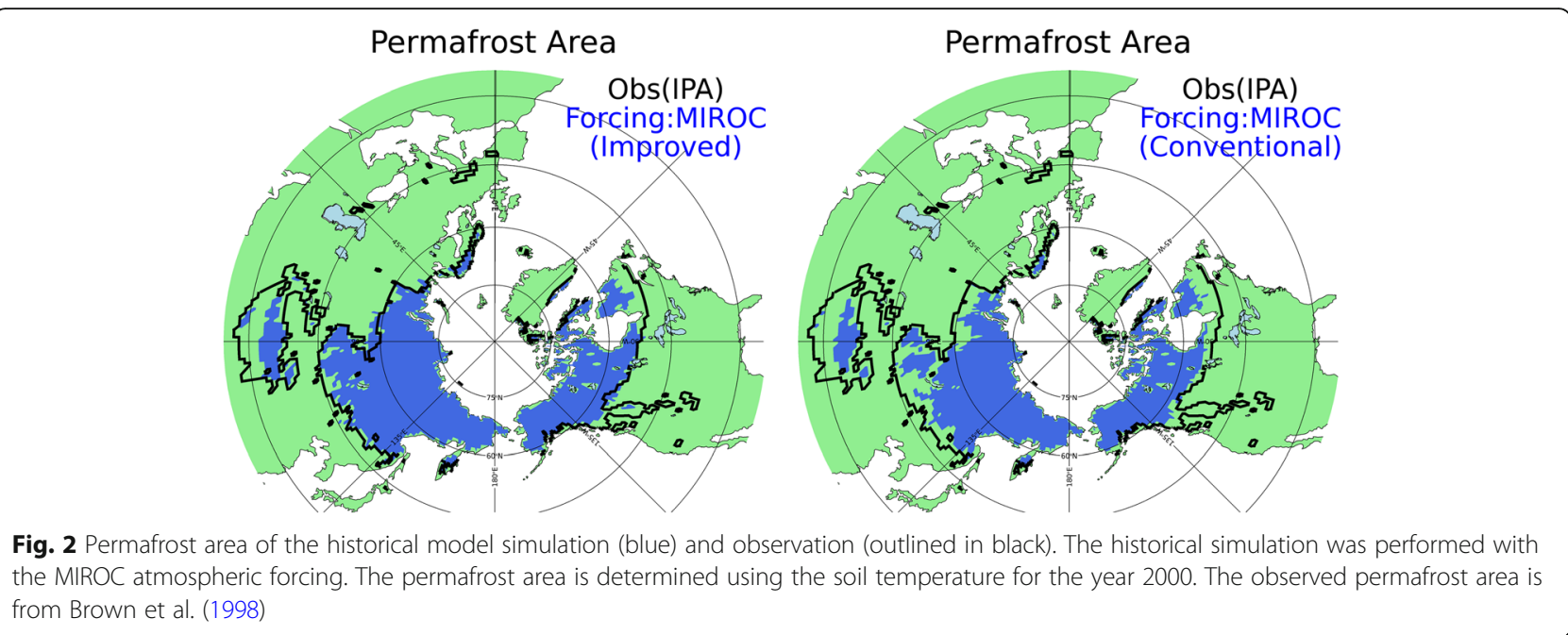

due to the presence of ice, and (c) the decrease in ground temperature in winter due to the presence of unfrozen water. In summer, factor (a) suppresses the soil temperature rise in the improved version compared to the conventional version. On the other hand, in winter, (b) and (c) promote a decrease in soil temperature.

Figure 3 shows the latitude-depth soil temperature distribution in the present climate. The upper panel of Fig. 3 shows the JJA, DJF, and annual average soil temperature distribution in the improved version. The soil temperature near the surface is higher than in the lower layer in the summer, but lower in winter. The vertical gradient of the soil temperature near the surface (to a depth of approximately $3 \mathrm{~m}$ ) is large, but becomes smaller with increasing depth. The annual average soil temperature is essentially determined according to latitude. The lower panel of Fig. 3 shows the difference in JJA, DJF, and annual average soil temperature between the improved and conventional versions. In summer, the soil temperature is lower in the improved version due to factor (a), the heat insulation effect of the organic layer. In winter, the soil temperature is higher in places due to the effect of (a), but is lower in many regions due to the effects of (b) and (c). For these reasons, in terms of the

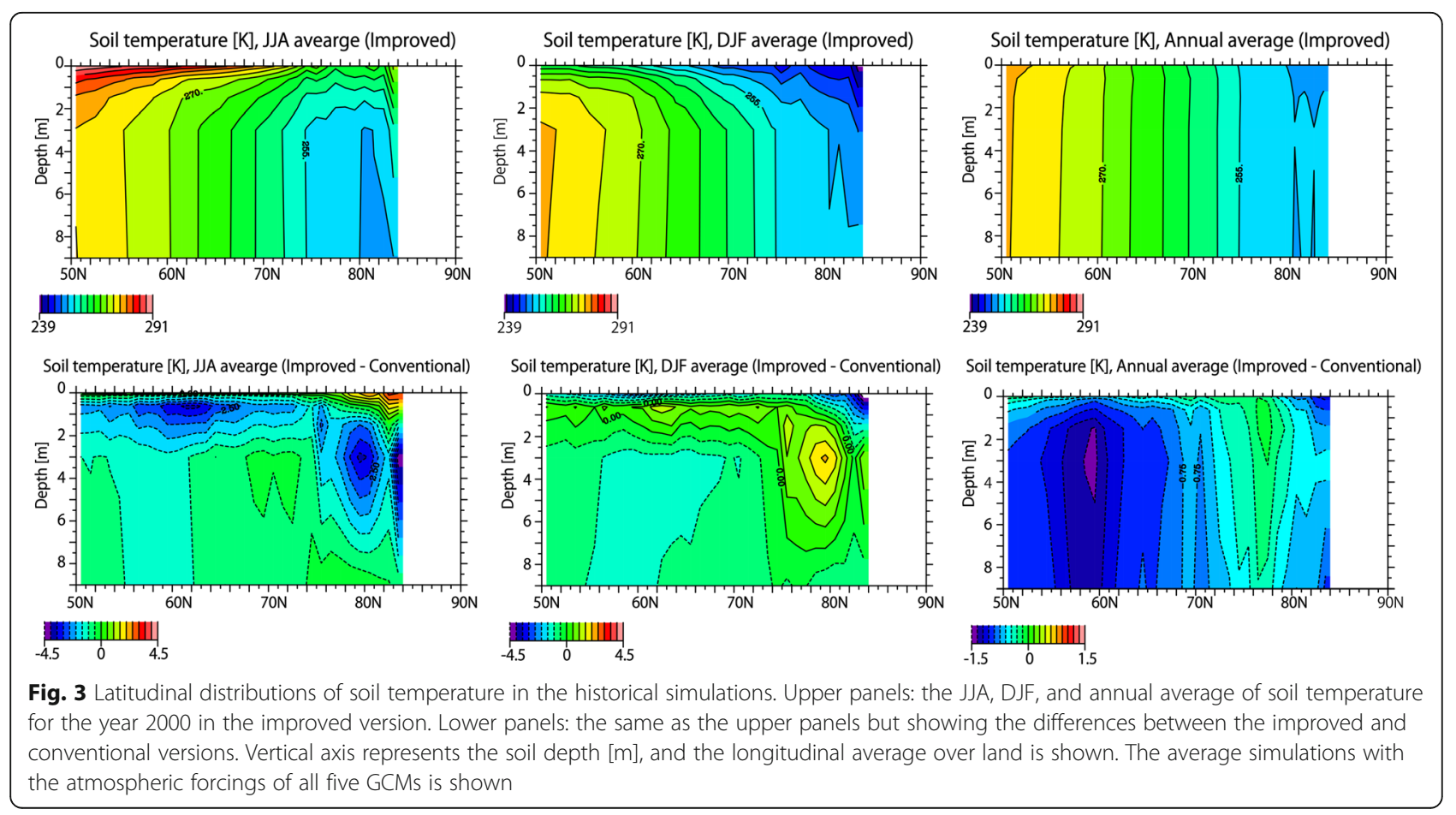




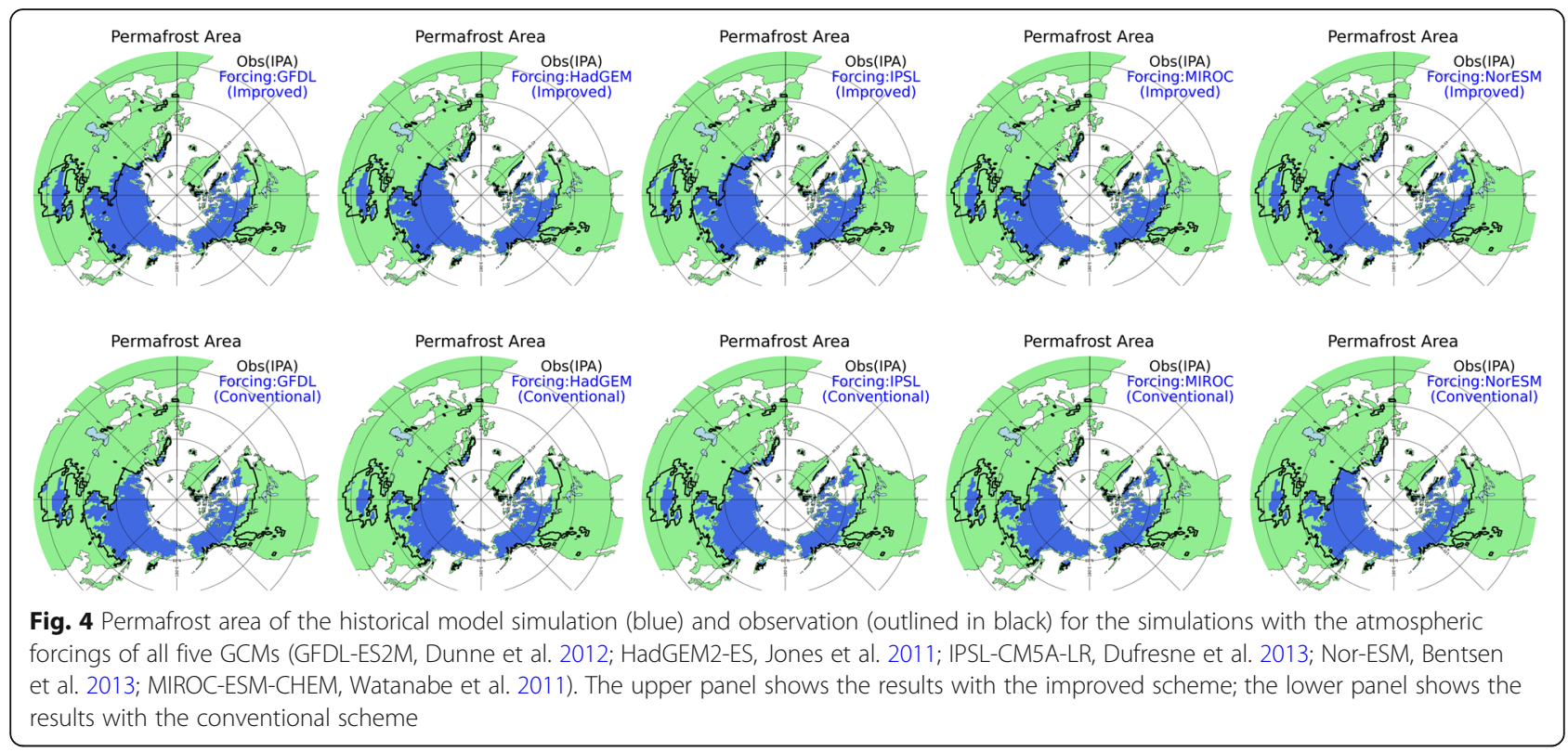

annual average value, the soil temperature is lower in the improved version over the entire area. As a consequence, the improved version has a larger distribution of permafrost, as shown in Fig. 2.

Figure 2 shows the simulation results when the atmospheric forcing of MIROC is given. The permafrost areas forced by all the various GCMs are shown in Fig. 4. The tendency of the permafrost area in the improved scheme to be larger and closer to the observed area than is the case for the conventional scheme is evident in all the simulation results forced by the five GCMs. More specifically, from the eastern part to the western part of Siberia, the improved version reproduces the southern limit of permafrost very well (reproducibility is especially high in GFDL and MIROC). On the other hand, from the eastern part to the western part of Siberia, the conventional version underestimates the permafrost distribution in all the simulations with different atmospheric forcings. Similarly, the improved version reproduces the southern limit of permafrost very well in central North America in all the simulations, while the permafrost area is underestimated in eastern and western Canada and the Himalayan region. This may be related to the fact that the global land surface model has a resolution of $1^{\circ}$ and that topographical details cannot be expressed, and thus permafrost is not reproduced adequately in the simulations.

Figure 5 compares the active layer thickness (ALT) in the model simulations with the observed values. We used the observation data obtained by Circumpolar Active Layer Monitoring (CALM) at the same forty sites that were used in Saito (2011). Here, a simulated ALT result in the grid cell closest to a CALM site was chosen. For the calculation of the ALT value from the model simulations, we chose the maximum depth of the model layers each year at which the soil temperature (monthly average) is larger than $0{ }^{\circ} \mathrm{C}$, following the procedure of Koven et al. (2015). The ALT value for the improved

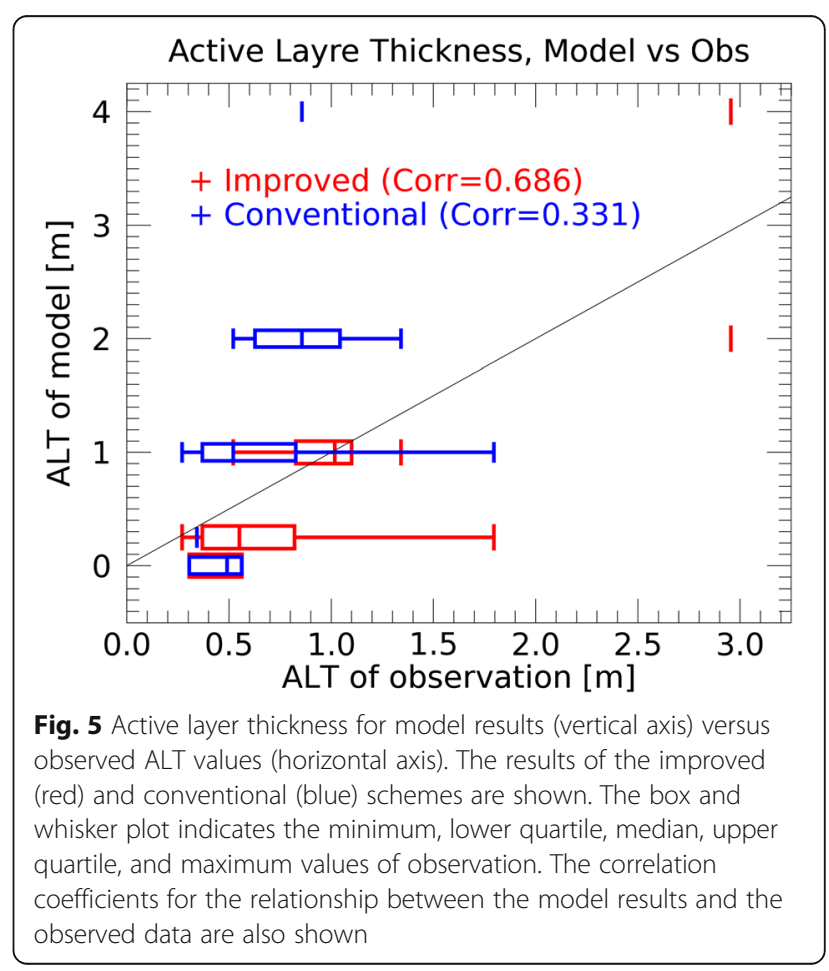


scheme is smaller than that for the conventional scheme, which is consistent with the results of the permafrost area comparison shown in Fig. 2. The correlation between the ALT values in the model simulations and the observed values in the improved and conventional schemes is 0.688 and 0.331 , respectively. Thus, the simulated ALT values for the improved scheme appear to be in better agreement with the observations than those in the conventional scheme. Given these results, we concluded that a more realistic treatment of the soil freezing processes can improve the reproducibility of the permafrost area in the model simulations.

\section{Future simulations}

Figure 6 shows future projections of the permafrost area using the improved and conventional schemes. Here, the permafrost area is diagnosed in the same way as in Fig. 2. Overall, the simulated response of the permafrost area to global warming is consistent with the features described above (Figs. 2, 3, 4, and 5). As shown in Fig. 6, the permafrost area decreases more rapidly under the conventional scheme than under the improved scheme. Figure 6 indicates that changes in the way in which the freezing processes are represented in the model greatly influence the model's projections of the future, as well as its description of the present.

A detailed comparison of the simulated changes in the permafrost area provides additional useful information. In both the improved and conventional schemes, the permafrost area decreases monotonically until the year 2040 (approximately) for both the RCP2.6 and RCP8.5 scenarios. After 2040 (approximately), the reduction rate of the permafrost area slows in the RCP2.6 scenario, while it accelerates in RCP8.5. More specifically, with the improved scheme, in the RCP8.5 scenario, the permafrost area decreases by an average of roughly $35 \%$ (average of the ensemble members) by 2100 , with a high estimate of 50\% (maximum of the ensemble members), while with the conventional scheme, the average decrease is roughly $60 \%$, with a high estimate of $80 \%$.

In order to investigate the differences in the permafrost distribution between the improved and conventional schemes, the time sequence of vertical distribution of soil temperature is shown in Fig. 7. As described above, the soil temperature near the surface is high in summer and low in winter, and the vertical gradient of soil temperature is small below $3 \mathrm{~m}$. As the air temperature rises through the twenty-first century, the soil temperature increases at all depths. As discussed above, the improved scheme considers (a) the organic layer near the surface, (b) the thermal conductivity of ice, and (c) unfrozen water. The effect of (a) suppresses the increase in soil temperature especially in summer and the effect of (a) is canceled by that of (b) and (c) in winter; thus, the annual average soil temperature in the improved scheme is lower than that in the conventional scheme over a wider area.

As shown in Fig. 7, the difference in summer soil temperature determines the difference in annual mean soil temperature between the improved and conventional schemes. Due to the effect of (a) in summer, the total heat flux reaching deep in the ground is larger in the conventional scheme than in the improved scheme. Since the difference in soil temperature is determined by the difference in the integrated amount of the heat flux reaching to the ground layers, the difference in soil temperature between the improved and conventional scheme increases with time. For this reason, the amount of permafrost reduction is larger in the conventional scheme than in the improved scheme.

Next, the difference in the permafrost change between the RCP2.6 and RCP8.5 scenarios in Fig. 4 is investigated. In this study, the future projection of surface air
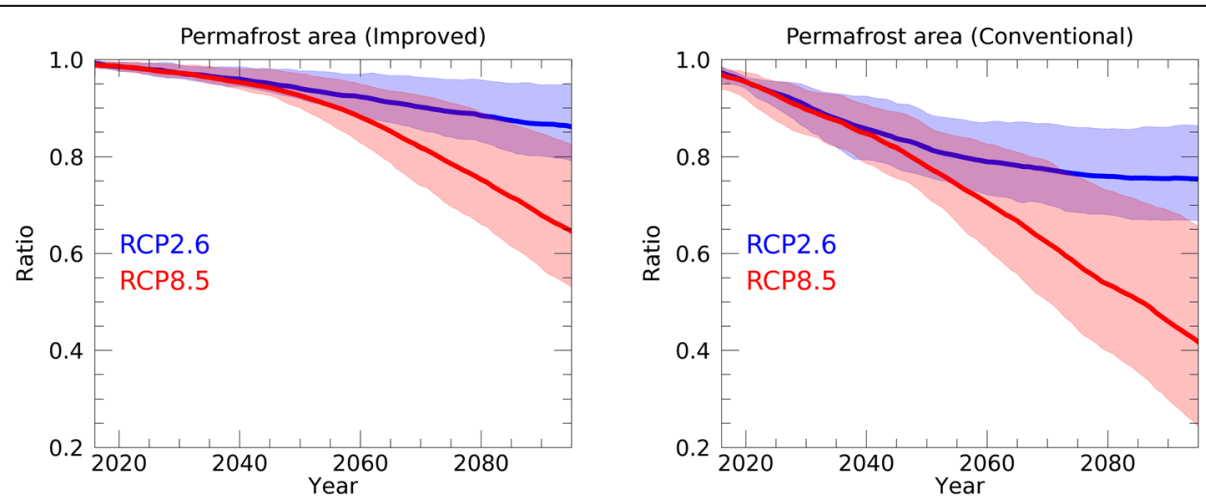

Fig. 6 Changes in the total permafrost area across the world as projected by the study's future simulations. The width of the line represents the maximum and minimum values of the simulated results forced by the five GCMs; the average value is represented by the bold lines. The simulations with the improved (left) and conventional (right) schemes under RCP2.6 (blue) and RCP8.5 (red) scenarios are shown. Values on the vertical axis were determined by setting the permafrost area at the initial year (2005) of the future simulations to 1.0 


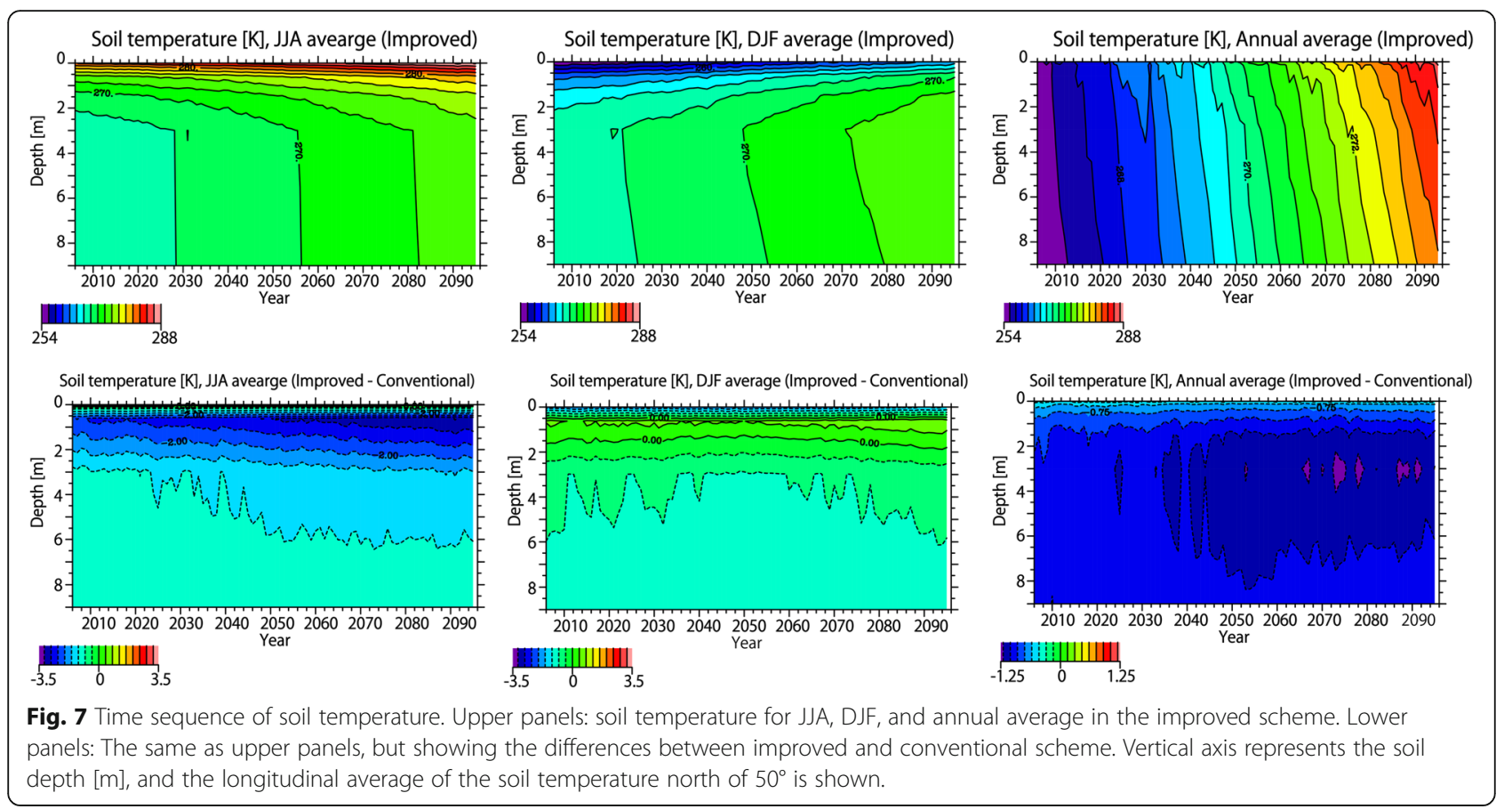

temperature by five GCMs is applied to the land surface model as the atmospheric forcing (Fig. 1). In the future projection of surface air temperature, the average values of the five GCMs under RCP2.6 and RCP8.5 are nearly the same until around 2030. Changes in the permafrost area (Fig. 4) are a delayed response to changes in surface air temperature, and the changes in permafrost areas in the two scenarios are nearly the same until around 2050 in the improved scheme. Figure 8 shows the difference in the vertical distributions of soil temperature between the RCP2.6 and RCP8.5 scenarios in the improved scheme. As indicated in Fig. 8, a difference in soil temperature between RCP2.6 and RCP8.5 begins to occur near the surface at around 2040, and it takes approximately 10 years to reach the bottom layer. As a result, differences in the permafrost area between RCP2.6 and RCP8.5 will appear roughly 20 to 30 years after the difference in surface air temperature between these scenarios occurs.

We also investigated the relationship between permafrost changes and global mean surface air temperature (Fig. 9). Burke et al. (2020) reported that permafrost sensitivity-the change in permafrost volume per degree of global mean surface air temperature change-is $20-30 \%$ using CMIP5/CMIP6 data. Although these authors analyzed the uncertainty ranges in multi-model ensembles of CMIPs, the present study could examine the response of a global land surface model by considering the uncertainty in atmospheric model projection. As shown in Fig. 9, permafrost sensitivity is similar for RCP2.6 and
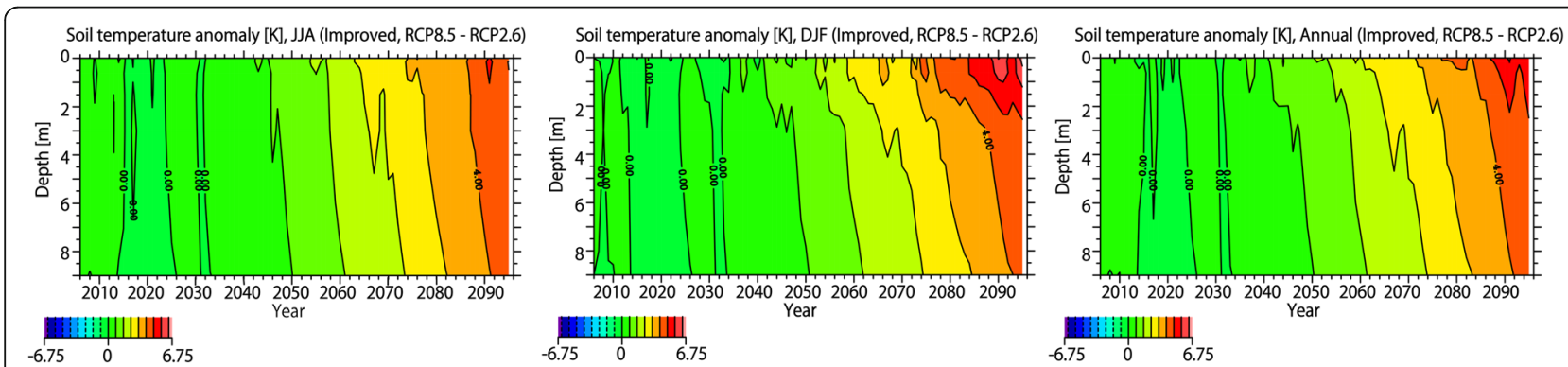

Fig. 8 Difference in soil temperature between RCP2.6 and RCP8.5. The time sequences of the vertical distribution of soil temperature for JJA, DJF, and annual average are shown. Vertical axis represents the soil depth [m], and the longitudinal average of the soil temperature north of $50^{\circ}$ is shown 

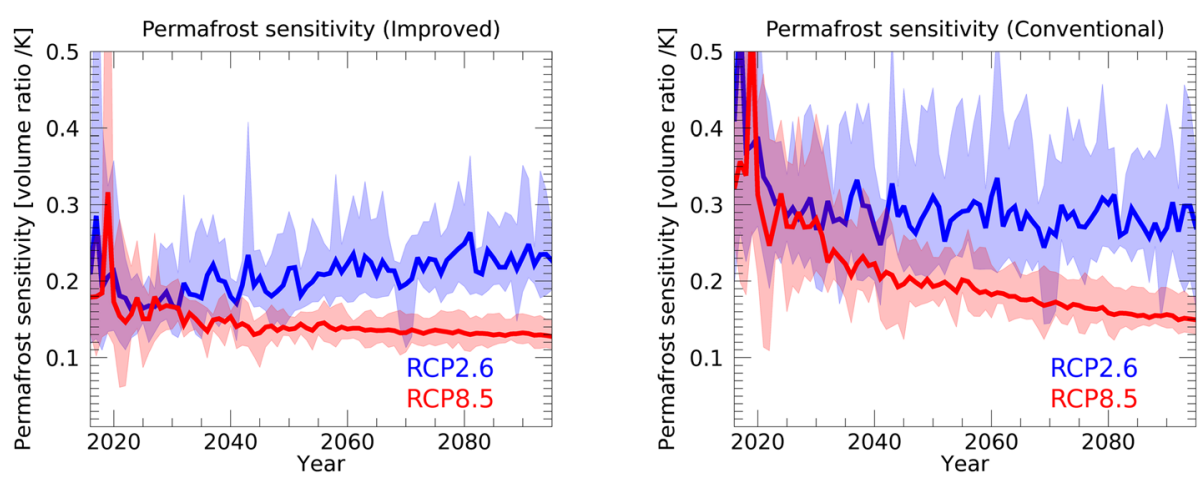

Fig. 9 Time sequence of permafrost sensitivity. The change in permafrost volume divided by the change in global mean surface air temperature [ratio/degree] is shown. The width of the colored bands represents the maximum and minimum values of the simulated results forced by the five GCMs; the average value is represented by the bold lines. The simulations with the improved (left) and conventional (right) schemes under RCP2.6 (blue) and RCP8.5 (red) scenarios are shown. Anomaly of permafrost volume and surface air temperature is calculated with respect to the 1995-2014 average.

RCP8.5 until around 2020. After 2040, a difference emerges, with RCP2.6 showing higher permafrost sensitivity. The reason for this higher sensitivity in RCP2.6 is that, in this scenario, the global mean surface air temperature stabilizes in the latter half of the twentyfirst century, which means changes in permafrost volume also stabilize during this time. In contrast, in $\mathrm{RCP} 8.5$, the global average temperature continues to rise throughout the century, and thus the response of soil temperature and permafrost volume is not stabilized. With the five atmospheric forcings in the improved scheme, the permafrost sensitivity in RCP2.6 is $0.2-0.3$ / ${ }^{\circ} \mathrm{C}$ at the end of the current century. On the other hand, the permafrost sensitivity for the RCP8.5 scenario in the improved scheme is $0.11-0.14 /{ }^{\circ} \mathrm{C}$, which is approximately half that for the RCP2.6 scenario.
Figure 10 shows the changes in the distribution of the permafrost regions with the improved and conventional schemes. As can be seen in the figure, the permafrost regions estimated with the conventional scheme retreats to higher latitudes than is the case for the improved scheme. On the North American continent, the permafrost regions with the conventional scheme decreases at the higher latitudes over most of the longitudinal band. In Siberia, the permafrost area is reduced around a latitude of $60^{\circ} \mathrm{N}$ within longitudes $90-135^{\circ} \mathrm{E}$ with the conventional scheme, but not so with the improved scheme (Fig. 10). On the other hand, the permafrost area does not decrease very much within longitudes of $90-135^{\circ} \mathrm{E}$.

Interestingly, reductions in the permafrost area differ depending on longitude, as shown in Fig. 10. The features of permafrost thawing must be related to the
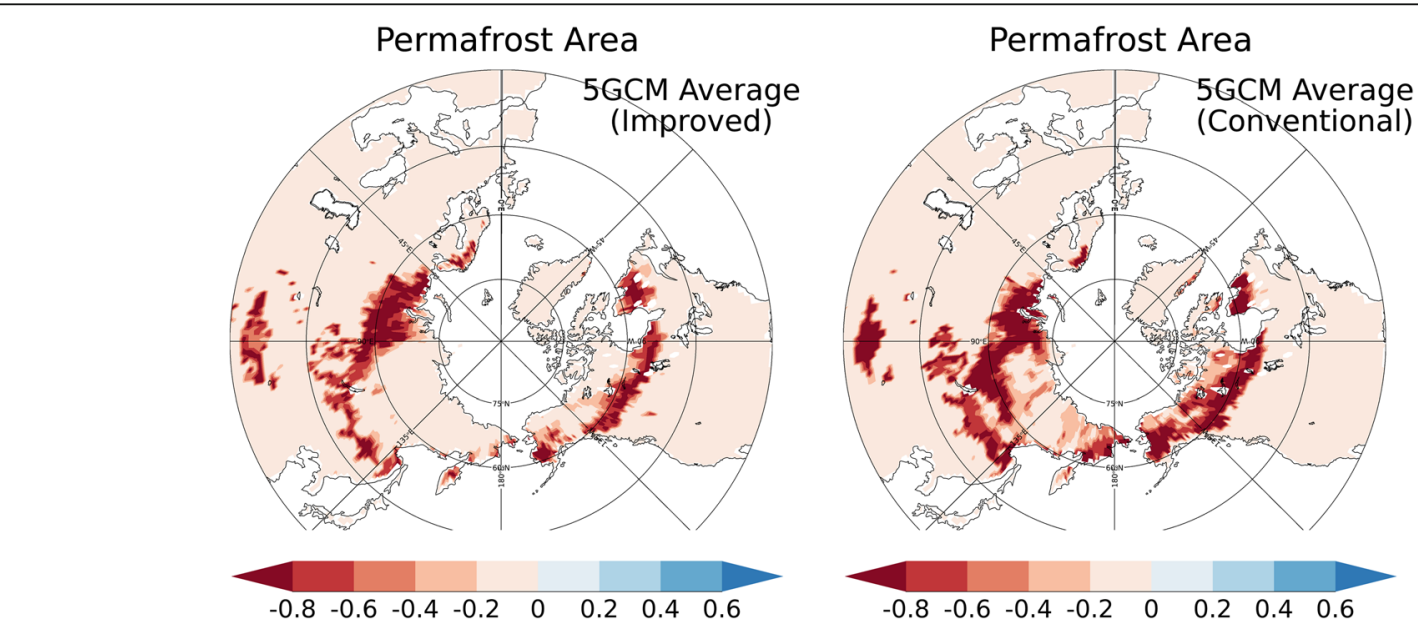

Fig. 10 Changes in the permafrost distribution projected by the study's future projection simulations. The current permafrost area is set at 1.0 . Average values for the simulations with atmospheric forcings by the five GCMs are plotted. The difference between the average for 2081-2090 and 2006-2015 under RCP8.5 was calculated 
different types of permafrost under the current climate, which varies greatly among different regions due to geological, geographical, and historical reasons. As indicated in Fig. 2, in the eastern part of the Eurasian continent (around longitudes $90-135^{\circ} \mathrm{E}$ ), permafrost exists in the lower latitudes to roughly $45^{\circ} \mathrm{N}$ (owing to the Tibetan Plateau). On the other hand, there is no permafrost area in the western part of the continent (around 0-90 ${ }^{\circ} \mathrm{E}$ ) below latitude $60^{\circ} \mathrm{N}$ (approximately) because of the temperate marine climate due to the Gulf Stream. These temperate climate conditions make the western part of the Eurasian continent (around 0-90 ${ }^{\circ} \mathrm{E}$ ) more prone to permafrost thawing (Fig. 10). Conversely, the permafrost regions in the eastern part of the Eurasian continent (or east Siberia, roughly $90-135{ }^{\circ} \mathrm{E}$ ) are less likely to be reduced because of the low surface air temperature, even at relatively low latitudes due to elevation. Figure 11 shows the future projections of the nearsurface soil temperature (top $5 \mathrm{~cm}$ ) in the RCP8.5 scenario simulated with the improved scheme. Although the changes in soil temperature are large in the eastern part of the Eurasian continent $\left(90-135^{\circ} \mathrm{E}\right.$, Fig. 11a), the soil temperature remains below $0{ }^{\circ} \mathrm{C}$, even at the end of the twenty-first century (Fig. 11b). In all, these findings confirm the proposition that future changes in the permafrost area are closely related to the features of current climate conditions and permafrost characteristics.

\section{Conclusions}

By refining the process associated with the freezing and thawing of soil moisture-which has been simplified in previous global climate models-the reproducibility of the model used here improved noticeably (Figs. 2 and 4).
In general, in order to ensure more reliable future projections, it is critical that a predictive model have the ability to accurately reproduce reality. The analysis in this study showed that the reproducibility of the featured model was enhanced by improving the sophistication of the basic freeze and thaw processes included in the model, particularly soil heat capacity and thermal conductivity. The findings reported here have the potential to greatly improve future projections of the permafrost area, which is an important physical quantity in climate change research.

According to a study evaluating the future projection results produced by the GCMs of the 5th Coupled Model Inter-comparison Project (CMIP5, Koven et al. 2015), the rate of decrease in the permafrost area for the RCP8.5 scenario was 30 to $100 \%$, with a high degree of uncertainty attached to the projections. Koven et al. (2015) used the results of 18 GCMs to quantify the uncertainties. However, the structure of the models (i.e., model parameterization, resolution) is quite different among the various CMIP5 GCMs (i.e., Knutti et al. 2013; Yokohata et al. 2013), making it difficult to precisely identify the causes of the uncertainties in the model projections. On the other hand, the analysis in this study revealed that the thermophysical properties (heat conduction and heat capacity) of the soil greatly affect the reproducibility of the current permafrost distribution (Figs. 2 and 4). Based on our analysis, it seems clear that a realistic treatment of such physical properties (e.g., thermophysical variables) is important to producing more realistic future projections.

A web page showing an animation of future permafrost change (Fig. 12, https://ads.nipr.ac.jp/node/dagik/ ?type=MIROC5/PERMAFROST_SEP) has been created

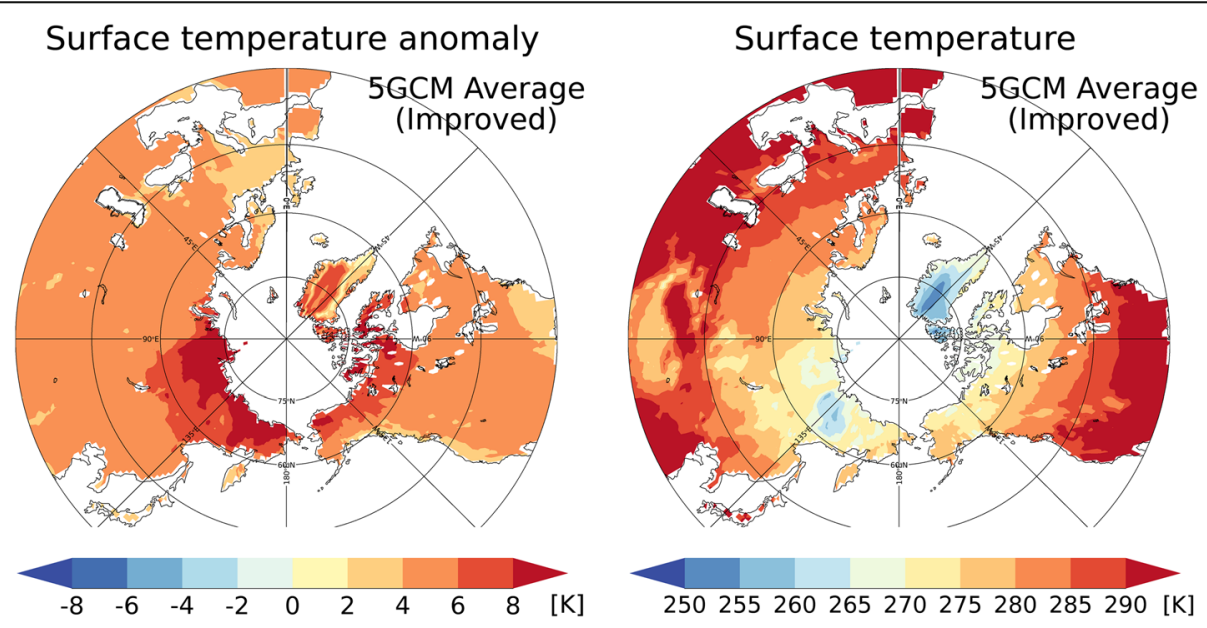

Fig. 11 Future projections of soil temperature changes. a Changes in the soil temperature (top 5 cm) between 2081-2090 and $2006-2015$ [K]; b Soil temperature (top $5 \mathrm{~cm}$ ) averaged over 2081-2090. The average values for the simulations with atmospheric forcings by the five GCMs are plotted 


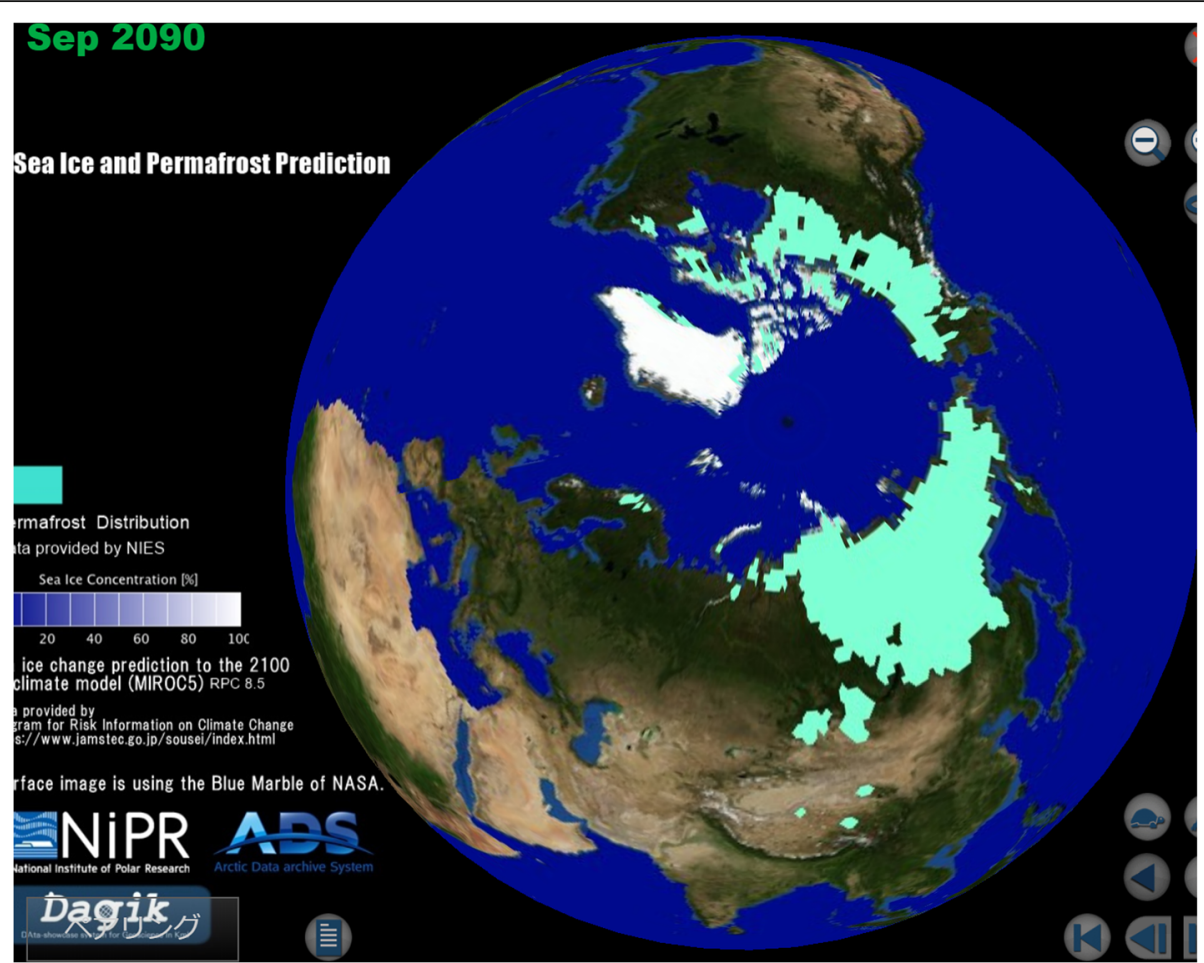

Fig. 12 Snapshot of an animation of future projections of the permafrost area based on data from simulations using the improved scheme with the MIROC atmospheric forcing under the RCP8.5 scenario. The animation was generated based on a tool developed by the Dagik Earth project (https://www.dagik.net/). The full animation is available at https://ads.nipr.ac.jp/node/dagik/?type=MIROC5/PERMAFROST_SEP

based on the future projection data that the authors provided to a research team at the National Institute of Polar Research specializing in such visualization (Arctic Data archive System). The animation was generated based on a tool developed by the Dagik Earth project (https://www.dagik.net/). On the created page, the center coordinates of the display (i.e., the angle of the projected map) can be freely changed by the viewer. With these animations, future projections indicating permafrost area reductions of as much as one-half are expressed in an easy-to-understand manner, not just for the general public, but for climate researchers as well.

\section{Abbreviations}

ALT: Active layer thickness; CLAM: Circumpolar Active Layer Monitoring: CMIP: Coupled Model Inter-comparison Project; GCM: Global climate model; GHGs: Greenhouse gases; IPA: International Permafrost Association; ISIMIP: Inter-Sectoral Impact Model Inter-comparison Project; MATS IRO: Minimal Advanced Treatments of Surface Interaction and Runoff; MIROC: Model for Interdisciplinary Research on Climate; RCP: Representative Concentration Pathways

\section{Acknowledgements}

We gratefully acknowledge the helpful discussions with Hideo Shiogama, Nagio Hirota, Kaoru Tachiiri, and Michio Kawamiya. The authors are much indebted to Keita Matsumoto, Kuniyasu Hamada, Kenryou Kataumi, Eiichi Hirohashi, Futoshi Takeuchi, Nobuaki Morita, and Kenji Yoshimura at NEC Corporation for their support in model development. Model simulations were performed on the SGI UV20 at the National Institute for Environmental Studies.

\section{Authors' contributions}

TY and KS proposed the topic and conceived and designed the study. TY and KS carried out the experimental study and analyzed the results of the numerical simulations. TN provided the original source code of the global land surface model. YS provided the forcing data for the land surface models. All authors have read and approved the final manuscript.

\section{Funding}

This study was conducted as a part of the Environment Research and Technology Development Fund project (2-1605, JPMEERF20162005) "Assessing and Projecting Greenhouse Gas Release from Large-scale Permafrost Degradation" supported by the Ministry of Environment and the Environmental Restoration and Conservation Agency. Our research was also supported by the "Integrated Research Program for Advancing Climate Models (TOUGOU Program)" sponsored by the Ministry of Education, Culture, Sports, Science and Technology (MEXT), Japan. This work was partially supported by the Arctic Challenge for Sustainability (ArCS), and the Arctic Challenge for Sustainability II (ArCS II), Program Grant Number JPMXD1420318865 sponsored by the MEXT, Japan. This study was partly supported by the NASA ABoVE (Arctic Boreal and Vulnerability Experiment (grant no. NNX17AC57A)).

\section{Availability of data and materials}

Data sharing is not applicable to this article as no datasets were generated or analyzed during the current study. Please contact the corresponding author for data requests.

\section{Competing interests}

The authors declare that they have no competing interests

\section{Author details}

${ }^{1}$ Center for Global Environmental Research, National Institute for Environmental Studies, 16-2 Onogawa, Tsukuba 305-8506, Japan. ${ }^{2}$ Research Institute for Global Change, Japan Agency for Marine-Earth Science and Technology, 3173-25 Showa-machi, Yokohama 236-0001, Japan. ${ }^{3}$ School of 
Life and Environmental Science, Azabu University, 1-17-71 Fuchinobe, Chuo-ku, Sagamihara-shi, Kanagawa 252-5201, Japan. ${ }^{4}$ Institute of Industrial Science, The University of Tokyo, 5-1-5 Kashiwanoha, Kashiwa, Chiba 277-8574, Japan. ${ }^{5}$ International Affairs and Research Development Office, National Institute for Polar Research, 10-3 Midori-cho, Tachikawa 190-8518, Japan. ${ }^{6}$ International Arctic Research Center, The University of Alaska Fairbanks, 2160 Koyukuk Dr, Fairbanks, AK 99775-7340, USA.

Received: 30 December 2019 Accepted: 9 October 2020

Published online: 13 November 2020

\section{References}

Alexeev V, Nicolsky D, Romanovsky V, Lawrence D (2007) An evaluation of deep soil configurations in the CLM3 for improved representation of permafrost. Geophys Res Lett 34:L09502. https://doi.org/10.1029/2007GL029536

Bentsen M, Bethke I, Debernard JB et al (2013) The Norwegian Earth System Model, NorESM1-M - Part 1: Description and basic evaluation of the physical climate. Geosci Model Dev 6(3):687-720. https://doi.org/10.5194/ gmd-6-687-2013

Brown A (2013) Pandora's freezer? Nat Climate Change 3(5):442-442. https:// doi.org/10.1038/nclimate1896

Brown J, Ferrians OJ, Heginbottom JA, Melnikov ES (1998, revised 2001) Circumarctic map of permafrost and ground ice conditions. National Snow and Ice Data Center, Digital media, Boulder, CO

Burke EJ, Zhang Y, Krinner G (2020) Evaluating permafrost physics in the Coupled Model Intercomparison Project 6 (CMIP6) models and their sensitivity to climate change. Cryosphere 14(9):3155-3174. https://doi.org/10.5194/tc-143155-2020

Chadburn SE, Burke EJ, Essery RLH, Boike J, Langer M, Heikenfeld M, Cox PM, Friedlingstein P (2015) Impact of model developments on present and future simulations of permafrost in a global land-surface model. Cryosphere 9:15051521

Dufresne J-L, Foujols M-A, Denvil S et al (2013) Climate change projections using the IPSL-CM5 Earth System Model: from CMIP3 to CMIP5. Climate Dyn 40: 2123-2165. https://doi.org/10.1007/s00382-012-1636-1

Dunne JP, John JG, Adcroft AJ et al (2012) GFDL's ESM2 Global Coupled Climate-Carbon Earth System Models. Part I: Physical Formulation and Baseline Simulation Characteristics. J Climate 25(19):6646-6665. https:// doi.org/10.1175/jcli-d-11-00560.1

Gasser T, Kechiar M, Ciais P et al (2018) Path-dependent reductions in CO2 emission budgets caused by permafrost carbon release. Nat Geosci 11(11): 830-835. https://doi.org/10.1038/s41561-018-0227-0

Gouttevin I, Krinner G, Ciais P, Polcher J, Legout C (2012) Multi-scale validation of a new soil freezing scheme for a land-surface model with physically-based hydrology. Cryosphere 6(2):407-430. https://doi.org/10. 5194/tc-6-407-2012

Hempel S, Frieler K, Warszawski L, Schewe J, Piontek F (2013) A trend-preserving bias correction \&ndash; the ISI-MIP approach. Earth Syst Dyn 4(2):219-236. https://doi.org/10.5194/esd-4-219-2013

Jones CD, Hughes JK, Bellouin N et al (2011) The HadGEM2-ES implementation of CMIP5 centennial simulations. Geosci Model Dev 4:543-570. https://doi.org/ 10.5194/gmd-4-543-2011

Kawamiya M, Hajima T, Tachiiri K, Yokohata T (2020) Two decades of earth system modelling, submitted to the same issue of Progress in Earth and Planetary Science, in press.

Knutti R, Masson D, Gettelman A (2013) Climate model genealogy: generation CMIP5 and how we got there. Geophys Res Lett 40(6):1194-1199. https://doi. org/10.1002/grl.50256

Koven C, Friedlingstein P, Ciais P, Khvorostyanov D, Krinner G, Tarnocai C (2009) On the formation of high-latitude soil carbon stocks: Effects of cryoturbation and insulation by organic matter in a land surface model. Geophys Res Lett 36:L21501. https://doi.org/10.1029/2009GL040150

Koven CD, Riley WJ, Stern A (2013) Analysis of permafrost thermal dynamics and response to climate change in the CMIP5 earth system models. J Climate 26(6):1877-1900. https://doi.org/10.1175/jcli-d-12-00228.

Koven CD, Schuur EA, Schadel C et al (2015) A simplified, data-constrained approach to estimate the permafrost carbon-climate feedback. Philos Trans A Math Phys Eng Sci 373(2054). https://doi.org/10.1098/rsta.2014.0423

Lawrence DM, Slater AG, Romanovsky VE, Nicolsky DJ (2008) Sensitivity of a model projection of near-surface permafrost degradation to soil column depth and representation of soil organic matter. J Geophys Res Earth Surf 113:F02011. https://doi.org/10.1029/2007JF000883

MacDougall AH, Knutti R (2016) Enhancement of non-CO2 radiative forcing via intensified carbon cycle feedbacks. Geophys Res Lett 43(11):5833-5840. https://doi.org/10.1002/2016gl068964

MacDougall AH, Zickfeld K, Knutti R, Matthews HD (2015) Sensitivity of carbon budgets to permafrost carbon feedbacks and non-CO2 forcings. Environ Res Lett 10(12):125003. https://doi.org/10.1088/1748-9326/10/12/125003

McGuire AD, Lawrence DM, Koven C et al (2018) Dependence of the evolution of carbon dynamics in the northern permafrost region on the trajectory of climate change. Proc Natl Acad Sci USA 115(15):3882-3887. https://doi.org/ 10.1073/pnas.1719903115

Melton JR, Verseghy DL, Sospedra-Alfonso R, Gruber S (2019) Improving permafrost physics in the coupled Canadian Land Surface Scheme (v.3.6.2) and Canadian Terrestrial Ecosystem Model (v.2.1) (CLASS-CTEM). Geosci Model Dev 12:4443-4467

Nicolsky D, Romanovsky V, Alexeev V, Lawrence D (2007) Improved modeling of permafrost dynamics in a GCM land-surface scheme. Geophys Research Lett 34(8):L08501. https://doi.org/10.1029/2007GL029525

Nitta T, Yoshimura K, Takata K et al (2014) Representing variability in subgrid snow cover and snow depth in a global land model: offline validation. J Climate 27(9):3318-3330. https://doi.org/10.1175/jcli-d-13-00310.1

Rinke A, Kuhry P, Dethloff K (2008) Importance of a soil organic layer for arctic climate: a sensitivity study with an Arctic RCM. Geophys Res Lett 35(13): L13709. https://doi.org/10.1029/2008GL034052

Saito K (2008a) Arctic land hydrothermal sensitivity under warming: Idealized offline evaluation of a physical terrestrial scheme in a global climate model. J Geophys Res 113(D21). https://doi.org/10.1029/2008jd009880

Saito K (2008b) Refinement of physical land scheme for cold-region subsurface hydrothermal processes and its impact on global hydro-climate. 9th International Conference on Permafrost, International Permafrost Association

Saito K (2011) Modeling freezing and thawing of subsurface soil layers for global climate models, In Druyan LM (ed) Climate Models, InTech, ISBN 979-953307-338-4. Chapter 9, 209-230

Saito K, Machiya H, Iwahana G (2020) Mapping simulated circum-Arctic organic carbon, ground ice, and vulnerability of ice-rich permafrost to degradation. Prog Earth Planet Sci 7(1):31. https://doi.org/10.1186/s40645-020-00345-z

Schaefer K, Lantuit H, Romanovsky VE, Schuur EAG, Witt R (2014) The impact of the permafrost carbon feedback on global climate. Environ Res Lett 9(8): 085003. https://doi.org/10.1088/1748-9326/9/8/085003

Schneider von Deimling T, Grosse G, Strauss J et al (2015) Observation-based modelling of permafrost carbon fluxes with accounting for deep carbon deposits and thermokarst activity. Biogeosciences 12(11):3469-3488. https:// doi.org/10.5194/bg-12-3469-2015

Schuur EAG, Bockheim J, Canadell JG et al (2008) Vulnerability of permafrost carbon to climate change: implications for the global carbon cycle. BioScience 58(8):701-714. https://doi.org/10.1641/b580807

Slater AG, Lawrence DM (2013) Diagnosing present and future permafrost from climate models. J Climate 26(15):5608-5623. https://doi.org/10.1175/ jcli-d-12-00341.1

Steffen W, Rockstrom J, Richardson K et al. (2018) Trajectories of the Earth System in the Anthropocene. Proc Natl Acad Sci U S A 115(33):8252-8259. https:// doi.org/10.1073/pnas.1810141115.

Takata K, Emori S, Watanabe T (2003) Development of the minimal advanced treatments of surface interaction and runoff. Glob Planet Change 38(1-2): 209-222. https://doi.org/10.1016/s0921-8181(03)00030-4

Vaks A, Gutareva OS, Breitenbach SFM et al (2013) Speleothems reveal 500,000year history of Siberian permafrost. Science 340(6129):183-186. https://doi. org/10.1126/science.1228729

van Vuuren DP, Edmonds J, Kainuma M et al (2011) The representative concentration pathways: an overview. Climatic Change 109(1-2):5-31. https://doi.org/10.1007/s10584-011-0148-z

Watanabe M, Suzuki T, O'ishi R et al (2010) Improved climate simulation by MIROC5: mean states, variability, and climate sensitivity. J Climate 23(23): 6312-6335. https://doi.org/10.1175/2010jcli3679.1

Watanabe S, Hajima T, Sudo K et al (2011) MIROC-ESM 2010: model description and basic results of CMIP5-20c3m experiments. Geoscientific Model Dev 4(4): 845-872. https://doi.org/10.5194/gmd-4-845-2011

Yokohata T, Annan JD, Collins M et al (2013) Reliability and importance of structural diversity of climate model ensembles. Climate Dynamics 41(9-10): 2745-2763. https://doi.org/10.1007/s00382-013-1733-9 
Yokohata T, Saito K, Ito A, Ohno H, Tanaka K, Hajima T, Iwahana G (2020) Future projection of climate change due to permafrost degradation with a simple numerical scheme. Prog Earth Planet Sci in press

Zimov SA, Davydov SP, Zimova GM et al (2006) Permafrost carbon: Stock and decomposability of a globally significant carbon pool. Geophys Res Lett 33(20). https://doi.org/10.1029/2006gl027484

\section{Publisher's Note}

Springer Nature remains neutral with regard to jurisdictional claims in published maps and institutional affiliations.

Submit your manuscript to a SpringerOpen ${ }^{\circ}$ journal and benefit from:

- Convenient online submission

- Rigorous peer review

- Open access: articles freely available online

- High visibility within the field

- Retaining the copyright to your article

Submit your next manuscript at $\boldsymbol{\wedge}$ springeropen.com 